\title{
Genetic characterization of a novel recombinant echovirus 30 strain causing a regional epidemic of aseptic meningitis in Hokkaido, Japan, 2017
}

\author{
Masahiro Miyoshi ${ }^{1}$ (D) Akiko Goto ${ }^{1} \cdot$ Rika Komagome $^{1} \cdot$ Hiroki Yamaguchi $^{1} \cdot$ Yuji Maruo $^{2} \cdot$ Masanori Nakanishi $^{2}$. \\ Setsuko Ishida ${ }^{1} \cdot$ Hideki Nagano $^{1} \cdot$ Takahisa Sugisawa $^{3} \cdot$ Motohiko Okano $^{1}$
}

Received: 11 July 2019 / Accepted: 26 October 2019 / Published online: 11 December 2019

(c) Springer-Verlag GmbH Austria, part of Springer Nature 2019

\begin{abstract}
A regional epidemic of aseptic meningitis caused by echovirus 30 (E30) occurred in Hokkaido, Japan, during the period of August-December 2017. To investigate their phylogenetic relationship to other human enteroviruses, we determined the complete genomic nucleotide sequences of isolates from this outbreak. Phylogenetic analysis of the viral capsid protein 1 gene showed that the strains were most closely related to E30 strains detected in Germany, France, and Russia in 2013. In contrast, the region encoding the viral protease and the RNA-dependent RNA polymerase had a close phylogenetic relationship to non-E30 enteroviruses detected in the United Kingdom and Switzerland in 2015-2017, suggesting that a recombination event had occurred.
\end{abstract}

Keywords Echovirus $30 \cdot$ Aseptic meningitis $\cdot$ Outbreak $\cdot$ Genetic characterization $\cdot$ Genome recombination

Echovirus 30 (E30) is one of the serotypes belonging to the species Enterovirus $B$ [1] and is a major pathogen causing aseptic meningitis (AM) in both children and adults. Large epidemics caused by E30 have been frequently reported globally [2]. We experienced a regional epidemic of AM caused by E30 in Hokkaido, Japan, during the period of August-December 2017. Details of the epidemic and the clinical features were presented previously [3]. In this study, we determined the complete nucleotide sequences of viruses from the outbreak to determine their molecular features and

Handling Editor: Chan-Shing Lin.

Electronic supplementary material The online version of this article (https://doi.org/10.1007/s00705-019-04484-7) contains supplementary material, which is available to authorized users.

Masahiro Miyoshi

miyo@iph.pref.hokkaido.jp

1 Hokkaido Institute of Public Health, North 19 West 12, Kita-ku, Sapporo 060-0819, Japan

2 Department of Pediatrics, Kushiro Red Cross Hospital, 21-14, Shinei-cho, Kushiro 085-8512, Japan

3 Kushiro Center of Public Health, 4-22, Shiroyama 2, Kushiro 085-0826, Japan their phylogenetic relationship to other strains of enterovirus B (EV-B). Virus isolation, RNA extraction, and sequencing were performed as described earlier [4]. Genome amplification and the nucleotide sequencing were carried out using specific primers (Supplementary Table S1). We determined the complete nucleotide sequences of four isolates, named E30/Hokkaido.JPN/21208 (Hokkaido21208), 21214, 21246, and 21326, that were collected on August 31, September 2 and 18, and November 24, 2017, and submitted them to the GenBank database under the accession numbers LC416533 to LC416536, respectively.

To investigate the genetic relationships of these isolates to globally circulating strains, phylogenetic analysis based on the viral capsid protein 1 (VP1) gene, the viral protease gene, and the RNA-dependent RNA polymerase (3CD) gene were carried out. Phylogenetic analysis based on the VP1 gene ( 876 bases) was performed in comparison with 248 E30 strains isolated in 33 countries during 1957-2017, and analysis based on the 3CD gene (1938 bases) was performed with 243 EV-B strains isolated in 33 countries during 19482017 (Supplementary Tables S2 and S3). With respect to choosing the strains, we took into account the genetic classifications of the strains that had been evaluated [2, 4-7]. Phylogenetic trees were constructed using Molecular Evolutionary Genetic Analysis software (MEGA v.5) [8], using 
the maximum-likelihood method based on the general timereversible model. The genetic lineages were confirmed by bootstrap values using 1000 pseudoreplicates [9]. Furthermore, the nucleotide sequences were aligned with those of 243 strains (Supplementary Table S3) of EV-B using MEGA

Table 1 Nucleotide and amino acid sequence identity between strain Hokkaido21208 and strain 13-759

\begin{tabular}{|c|c|c|}
\hline Genomic region & $\begin{array}{c}\text { No. of Nucleotide/ } \\
\text { Amino acid } \\
\text { (base/residue) }\end{array}$ & $\begin{array}{c}\text { Each Identity } \\
\text { (\%) }\end{array}$ \\
\hline 5'UTR & 742 / - & 96.0 / - \\
\hline \multicolumn{3}{|l|}{ P1 } \\
\hline VP4 & $210 / 70$ & $94.3 / 95.7$ \\
\hline VP2 & $780 / 260$ & $96.2 / 99.6$ \\
\hline VP3 & $714 / 238$ & $95.8 / 99.6$ \\
\hline VP1 & $876 / 292$ & $96.1 / 99.3$ \\
\hline \multicolumn{3}{|l|}{ P2 } \\
\hline $2 \mathrm{~A}$ & $450 / 150$ & $95.1 / 98.0$ \\
\hline $2 B$ & $297 / 99$ & $92.3 / 96.0$ \\
\hline $2 \mathrm{C}$ & $987 / 329$ & $84.0 / 98.2$ \\
\hline \multicolumn{3}{|l|}{ P3 } \\
\hline $3 A$ & $267 / 89$ & 78.7 /96.6 \\
\hline $3 B$ & $66 / 22$ & $71.2 / 90.9$ \\
\hline $3 C$ & $549 / 183$ & $79.2 / 96.7$ \\
\hline $3 D$ & $1389 / 462$ & $80.3 / 97.0$ \\
\hline 3'UTR & $101 /-$ & 79.2 / - \\
\hline
\end{tabular}

Black arrow indicates the predicted recombination breakpoint. v.5. The gap-opening and extension penalties were set to 15 and 6.66, respectively, and the alignments were corrected manually to match the open reading frame (ORF). In order to identify potential recombination sites in the genome, a similarity plot analysis was performed using Simplot software version 3.5.1 [10] with a sliding window of 400 nucleotides moving in steps of 50 nucleotides.

The genomes of four E30 strains from Hokkaido consisted of 7428 nucleotides including a 5' untranslated region (UTR) of 742 nucleotides followed by an ORF encoding a polypeptide of 2194 amino acids and a 3' UTR of 101 nucleotides. The nucleotide and amino acid sequences of these strains were highly conserved (99.6-9\% and 99.8-9\% identity), suggesting that a single lineage of E30 had spread. The sequence of the 5' UTR and the P1 genomic region of the strain Hokkaido21208 showed the highest identity to those of the strain 13-759, which was isolated in Germany in 2013 [11] (Table 1). While a high degree of nucleotide sequence similarity was also found in the $2 \mathrm{~A}$ and the $2 \mathrm{~B}$ genes, the sequence identity values from the $2 \mathrm{C}$ gene to the 3' UTR were considerably lower (ranging from $71.2 \%$ to $84.0 \%$ ). However, despite this divergence, the amino acid identity values from the $\mathrm{P} 1$ region to the $\mathrm{P} 3$ region ranged from $90.9 \%$ to $99.6 \%$ (Table 1 ).

The result of similarity plot analysis correlated with the above results (Fig. 1). From the 5' UTR to the $2 \mathrm{~B}$ gene, the
Fig. 1 Similarity plot analysis comparing strain Hokkaido21208 with EV-B strains. The nucleotide sequence of strain Hokkaido21208 was compared with those of 223 strains of EV-B (Supplementary Table S3), using Simplot software version 3.5.1 with a sliding window of 400 nucleotides moving in steps of 50 nucleotides. The strains described in this article are indicated by colored lines, and other strains are indicated by gray lines

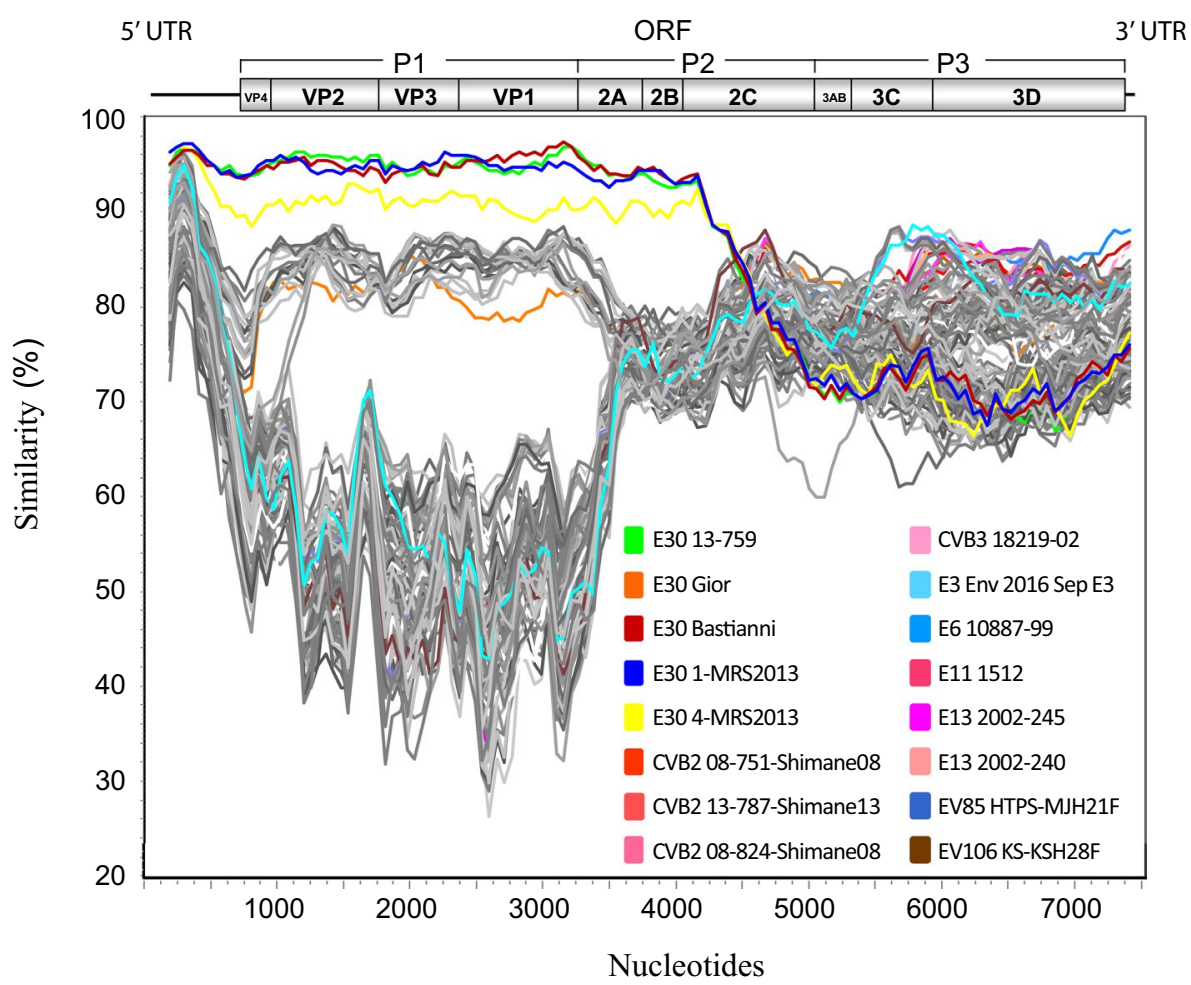


strain Hokkaido21208 was most closely related to the strain 13-759. However, the similarity of the $2 \mathrm{C}$ gene dropped abruptly to the same level as with other serotypes of EV-B. By contrast, the genomic region between the $2 \mathrm{C}$ gene and the 3' UTR of the strain Hokkaido21208 did not show significant similarity to any of the strains compared, suggesting that a recombination event had occurred at the border between the $2 \mathrm{~B}$ and $2 \mathrm{C}$ genes. This breakpoint has been previously identified as a recombination hot spot [12].

A previous study indicated that the VP1 genes of E30 detected in Japan before 1998 were divided into six genogroups [5]. These genogroups correspond to the lineages E30_d, e, and g based on an advanced report by Bailly et al. [6]. In this study, our analysis indicated that the Hokkaido strains belong to the lineage E30_f (Fig. 2A), forming a novel cluster with Japanese strains detected in Fukushima prefecture, and with German, French, and Russian strains detected during 2008-2014. In contrast, several Japanese strains detected during 2008-2014 in Toyama, Osaka, Oita, and Okinawa prefectures, located mainly in western Japan, were classified in lineage E30_b (Fig. 2A). These data suggest that the Hokkaido strains might have originated overseas, in particular, Europe. E30 strains have been detected almost every year in Japan [13]. However, due to insufficient genetic information of these isolates, the detailed phylogenetic and topological relationships among Japanese strains and the time point of importation of lineage E30_f could not be clarified.

Amino acid substitutions in VP1 of the Hokkaido strains were found in at least 20 positions in comparison with the strain 25-0284/osaka.AB908259/JPN/2013, which belongs to lineage E30_b (Table 2). Among these sites, 13 substitutions $(56 \mathrm{Y} / \mathrm{F}, 87 \mathrm{E} / \mathrm{D}, 120 \mathrm{I} / \mathrm{V}, 145 \mathrm{~V} / \mathrm{I}, 156 \mathrm{R} / \mathrm{K}, 157 \mathrm{~S} / \mathrm{G}$, $234 \mathrm{~N} / \mathrm{S}, 247 \mathrm{~K} / \mathrm{R}, 269 \mathrm{~V} / \mathrm{I}, 274 \mathrm{E} / \mathrm{D}, 284 \mathrm{~S} / \mathrm{T}, 285 \mathrm{~T} / \mathrm{N}$, and 289L/M) showed divergence from these lineages. Codons 87 and 156, which comprise a portion of the BC loop and the EF loop, respectively, have been predicted not only to be exposed on the surface but also to represent putative positive selection sites [6, 14]. Besides, several substitutions are in the C-terminal region of VP1 (amino acids 260-292), which has been recognized as one of the main antigenic regions of enteroviruses [15-17]. The emergence of an epidemic would implicitly indicate the lack of herd immunity in the community. Furthermore, the novel strains, which have different antigenic properties, even within the same serotype, could have escaped the host's immune system. Earlier studies have demonstrated that E30 is antigenically heterogeneous and divided into three major groups $[18,19]$. The VP1 nucleotide sequences of these groups are classified into the lineage E30_a or c, while the differences in antigenic properties do not correlate with the comprehensive classification [6]. Under these circumstances, it is important to explore whether the strains are pathogenic and able to spread beyond a regional scale in the near future. However, the strain-specific features that might be involved in disease are still not well understood [11, 20], and more-detailed study is needed to evaluate the characteristics of each lineage and to understand the potential endemic risk and the dynamics of virus transmission.

The 3CD genes of EV-B are divided phylogenetically into three groups (1, 2, and 3) (Fig. 2B) [4, 7]. Our findings indicate that the Hokkaido strains belong to group 3 and form a cluster with coxsackievirus type B2 (CVB2), CVB3, CVB4, CVB5, E3, E6, E11, E13, enteroviruses 85, and B106 strains detected in European and Asian countries during the last 20 years. Among these strains, CVB4, CVB5, and E3 strains detected in the United Kingdom and Switzerland during 2015-2017 occupied the nearest branch (Fig. 2B). No other E30 strain except for the Hokkaido strains was found in this cluster. In contrast, the E30 strain 13-759, whose VP1 gene showed a high degree of similarity to those of the Hokkaido strains, was classified into group 2. Group 2 included several EV-B strains detected intermittently in Europe, suggesting that this genome has been maintained there since the previous century (Fig. 2B) [6]. In addition to the data for the VP1 genes described above, chronological and phylogenetic information about the $3 \mathrm{CD}$ genes strongly suggest that the Hokkaido E30 strains originated in Europe.

The emergence of E30 has been found to exhibit a cyclic pattern with dominance and disappearance of individual recombinants over a period of years [21-27]. The turnover period for such recombinants has been calculated to be from 1.8 to 5 years $[28,29]$. Therefore, long-term surveillance based on detection of virus in clinical specimens and environmental materials would contribute to our understanding trends and epidemiological patterns [30-34]. Furthermore, investigation of the antigenic properties of circulating viruses is fundamental to understand their pathogenic features and, ultimately, to promote measures that are important for preventive public health. 
(A)

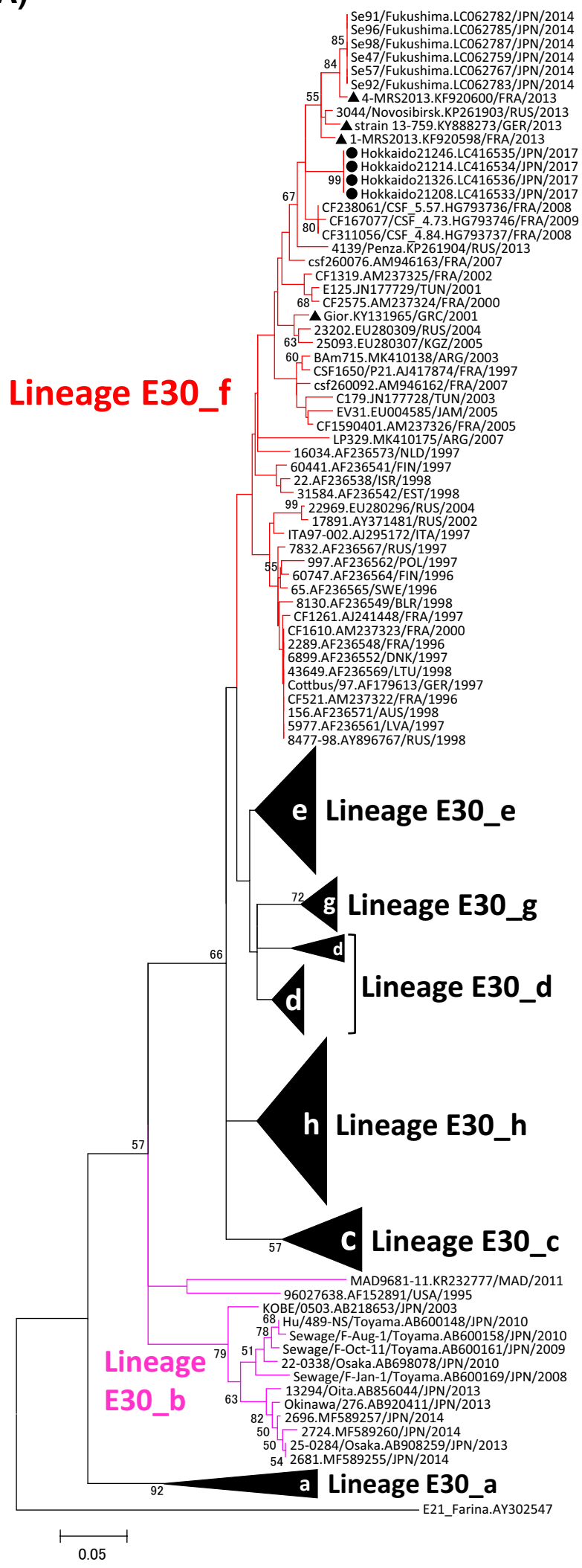

(B)

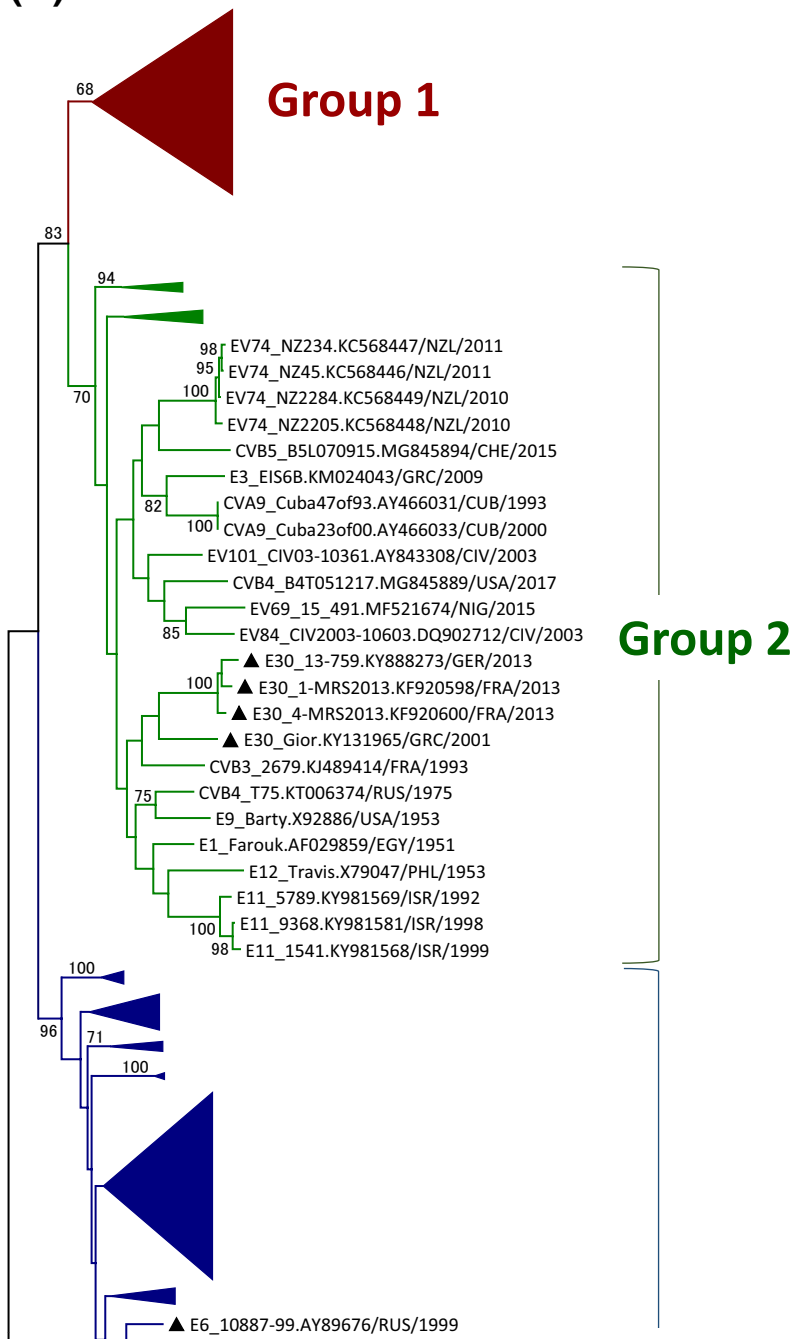

94_E6_NSW-V18.MF678307/AUS/2007 E6_RA/E6/Ahvaz.KX619440/IRN/2011

- A EV106_KS-KSH28F/XJ.KX171336/CHN/2011 A CVB2 13-787-Shimane13.LC191406/JPN/2013

Group 3 100 CVB2 NS13-006-Nagasaki13.LC191413/JPN/2013 100 CVB2_NS13-010-Nagasaki13.LC191416/JPN/2013 [ C CVB2_08-824-Shimane08.LC191402/JPN/2008 100 CVB2_08-751-Shimane08.LC191400/JPN/2008 —E11 1512.KY981566/ISR/1999

88. $\Delta$ E13_2002-245-NP.AB501330/JPN/2002 E13_I5(1)/1.AB501331/JPN/2002 100 E13 S3(1)-1.AB501332/JPN/2002

A E13 2002-240-SF.AB501329/JPN/2002

—_ CVB3_18219-02.AY896763/MDA/2002

98 EV85_ARLH403F/XJ.JX898905/CHN/2011

51 EV85_AFP02F/XJ.JX898909/CHN/2011

EV85 HTPS-MKLH04F/XJ.JX898907/CHN/2011

00 EV85_HT-LYKH202F/XJ.JX898908/CHN/2011

\ EV85_HTPS-MJH21F/XJ.JX898906/CHN/2011

99_- $\Delta$ E3_Env_2016_Sep_E3.MG451804/GBR/2016 92 LCVB5 B5L060815.MG845891/GBR/2015

_CVB4_Env 2017_Jan.MG451808/GBR/2017

E30_Hokkaido21208.LC416533/JPN/2017

E30_Hokkaido21208.LC416533/JPN/2017

E30 Hokkaido21246.LC416535/JPN/2017

- E30_Hokkaido21214.LC416534/JPN/2017 - Polio_Sabin_1.AY184219 
4Fig. 2 Phylogenetic trees based on the VP1 genes of E30 strains and the 3CD genes of EV-B strains. (A) Phylogenetic tree based on the VP1 genes of E30 strains. (B) Phylogenetic tree based on the 3CD genes of EV-B strains. Bootstrap values above $50 \%$ are shown at the nodes. The scale bar represents nucleotide substitutions per site. Black circles indicate the Hokkaido strains. Black triangles indicate the strains highlighted in Fig. 1

Table 2 Amino acid substitutions in VP1 of E30 strains detected in Japan after 2010

\begin{tabular}{|c|c|c|c|c|c|c|c|c|c|c|c|c|c|c|c|c|c|c|c|c|c|c|}
\hline \multirow[t]{4}{*}{ Strain } & \multirow[t]{4}{*}{ Lineage } & \multicolumn{21}{|c|}{ Amino acid number } \\
\hline & & & & & 1 & 1 & 1 & 1 & 1 & 2 & 2 & 2 & 2 & 2 & 2 & 2 & 2 & 2 & 2 & 2 & 2 & 2 \\
\hline & & 5 & 8 & 8 & 1 & 2 & 4 & 5 & 5 & 0 & 3 & 4 & 6 & 6 & 7 & 7 & 8 & 8 & 8 & 8 & 8 & 9 \\
\hline & & 6 & 4 & 7 & 0 & 0 & 5 & 6 & 7 & 4 & 4 & 7 & 3 & 9 & 4 & 7 & 4 & 5 & 7 & 8 & 9 & 0 \\
\hline Hokkaido strains/2017 & $\mathrm{f}$ & $\mathrm{Y}$ & $\mathrm{V}$ & $\mathrm{E}$ & M & I & V & $\mathrm{R}$ & $\mathrm{S}$ & $\mathrm{S}$ & $\mathrm{N}$ & $\mathrm{K}$ & $\mathrm{R}$ & $\mathrm{V}$ & $\mathrm{E}$ & $\mathrm{G}$ & $\mathrm{S}$ & $\mathrm{T}$ & $\mathrm{N}$ & $\mathrm{P}$ & $\mathrm{L}$ & $\mathrm{S}$ \\
\hline Se47/Fukushima/2014 & $\mathrm{f}$ & . & $\mathrm{T}$ & . & . & . & . & . & . & . & . & . & . & . & . & . & . & . & . & . & . & $\cdot$ \\
\hline Se91/Fukushima/2014 & $\mathrm{f}$ & . & $\mathrm{T}$ & . & . & . & . & . & . & . & . & . & . & . & . & . & . & . & . & $\mathrm{L}$ & . & . \\
\hline Se98/Fukushima/2014 & $\mathrm{f}$ & . & $\mathrm{T}$ & . & . & . & . & . & . & . & . & . & . & . & . & . & . & . & . & . & . & $\mathrm{L}$ \\
\hline 25-0284/Osaka/2013 & $\mathrm{b}$ & $\mathrm{F}$ & A & $\mathrm{D}$ & . & V & I & $\mathrm{K}$ & G & $\mathrm{N}$ & $\mathrm{S}$ & $\mathrm{R}$ & $\mathrm{K}$ & I & $\mathrm{D}$ & $\mathrm{S}$ & $\mathrm{T}$ & $\mathrm{N}$ & G & $\mathrm{V}$ & M & $\mathrm{K}$ \\
\hline 22-0338/Osaka/2010 & $\mathrm{b}$ & $\mathrm{F}$ & A & $\mathrm{D}$ & . & V & I & $\mathrm{K}$ & G & $\mathrm{N}$ & $\mathrm{S}$ & $\mathrm{R}$ & $\mathrm{K}$ & I & $\mathrm{D}$ & $\mathrm{S}$ & $\mathrm{T}$ & $\mathrm{N}$ & $\mathrm{S}$ & A & M & M \\
\hline 489-NS/Toyama/2010 & $\mathrm{b}$ & $\mathrm{F}$ & A & $\mathrm{D}$ & . & V & I & $\mathrm{K}$ & G & . & $\mathrm{S}$ & $\mathrm{R}$ & . & I & $\mathrm{D}$ & $\mathrm{F}$ & $\mathrm{T}$ & $\mathrm{N}$ & $*$ & $*$ & $*$ & $*$ \\
\hline F-Aug-1/Toyama/2010 & $\mathrm{b}$ & $\mathrm{F}$ & A & $\mathrm{D}$ & I & $\mathrm{V}$ & I & $\mathrm{K}$ & $\mathrm{G}$ & $\mathrm{N}$ & $\mathrm{S}$ & $\mathrm{R}$ & . & I & $\mathrm{D}$ & $\mathrm{S}$ & $\mathrm{T}$ & $\mathrm{N}$ & $*$ & $*$ & $*$ & $*$ \\
\hline
\end{tabular}

Dots (.) indicate amino acid residues identical to those in the Hokkaido strains

Asterisks (*) indicate that there was no sequencing information

Acknowledgements The authors are grateful to the staffs of local hospitals, the Kushiro Center of Public Health, and the Department of Health and Welfare, Hokkaido Government, for collecting samples and providing the epidemiological information.

Funding This work was financially supported by a grant-in-aid for scientific research from the Hokkaido Government, Japan.

\section{Compliance with ethical standards}

Conflict of interest The authors declare no conflict of interest.

\section{References}

1. Adams MJ, Lefkowitz EJ, King AMQ et al (2017) Changes to taxonomy and the international code of virus classification and nomenclature ratified by the international committee on taxonomy of viruses. Arch Virol 162:2505-2538
2. Lema C, Torres C, Van der Sanden S et al (2019) Global phylodynamics of Echovirus 30 revealed differential behavior among viral lineages. Virology 531:79-92

3. Maruo Y, Nakanishi M, Suzuki Y et al (2019) Outbreak of aseptic meningitis caused by echovirus 30 in Kushiro, Japan in 2017. J Clin Virol 116:34-38

4. Miyoshi M, Komagome R, Ishida S et al (2013) Genomic characterization of echovirus 6 causing aseptic meningitis in Hokkaido, Japan: a novel cluster in the nonstructural protein coding region of human enterovirus B. Arch Virol 158:775-784

5. Yoshida H, Hong Z, Yoneyama T et al (1999) Phylogenic analysis of echovirus type 30 isolated from a large epidemic of aseptic meningitis in Japan during 1997-1998. Jpn J Infect Dis 52:160-163

6. Bailly JL, Mirand A, Henquell C et al (2009) Phylogeography of circulating populations of human echovirus 30 over 50 years: nucleotide polymorphism and signature of purifying selection in the VP1 capsid protein gene. Infect Genet Evol 9:699-708

7. Chu PY, Tyan YC, Chen YS et al (2015) Transmission and Demographic Dynamics of Coxsackievirus B1. PLoS One 10:e0129272

8. Tamura K, Peterson D, Peterson N et al (2011) MEGA5: molecular evolutionary genetics analysis using maximum likelihood, evolutionary distance, and maximum parsimony methods. Mol Biol Evol 28:2731-2739 
9. Felsenstein J (1985) Confidence limits on phylogenies: An approach using the bootstrap. Evolution 39:783-791

10. Lole KS, Bollinger RC, Paranjape RS et al (1999) Full-length human immunodeficiency virus type 1 genomes from subtype $\mathrm{C}$-infected seroconverters in India, with evidence of intersubtype recombination. J Virol 73:152-160

11. Dahm T, Adams O, Boettcher S et al (2018) Strain-dependent effects of clinical echovirus 30 outbreak isolates at the blood-CSF barrier. J Neuroinflammation 15:50

12. Lukashev AN, Lashkevich VA, Ivanova OE et al (2005) Recombination in circulating Human enterovirus B: independent evolution of structural and non-structural genome regions. J Gen Virol $86: 3281-3290$

13. National Institute of Infectious Diseases and Tuberculosis and Infectious Diseases Control Division, Ministry of Health, Labour and Welfare (2018) Viruses detected from aseptic meningitis patients in Japan, through 2017. Infect Agents Surveill Rep 39:1'(89')-2'(90') (Article in Japanese)

14. Muckelbauer JK, Kremer M, Minor I et al (1995) The structure of coxsackievirus B3 at $3.5 \AA$ resolution. Structure 3:653-667

15. Henquell C, Mirand A, Richter J et al (2013) Phylogenetic patterns of human coxsackievirus B5 arise from population dynamics between two genogroups and reveal evolutionary factors of molecular adaptation and transmission. J Virol 87:12249-12259

16. Palacios G, Casas I, Cistema D et al (2002) Molecular epidemiology of echovirus 30: temporal circulation and prevalence of single lineages. J Virol 76:4940-4949

17. Pulli T, Lankinen H, Roivainen M, Hyypiä T (1998) Antigenic sites of coxackievirus A9. Virology 240:202-212

18. Duncan IB (1968) A comparative study of 63 strains of ECHO virus type 30. Arch Gesamte Virusforsch 25:93-104

19. Wenner HA, Hamon P, Behbehani AM et al (1967) The antigenic heterogeneity of type 30 echoviruses. Am J Epidemiol $85: 240-249$

20. Sun Q, Zhang Y, Zhu S et al (2013) Transmission of human enterovirus 85 recombinants containing new unknown serotype HEV-B donor sequences in Xinjiang Uighur Autonomous Region, China. PLoS One 8:E55480

21. Chen Y, Sun Y, Yan J et al (2017) Molecular epidemiology and prevalence of echovirus 30 in Zhejiang Province, China, from 2002 to 2015. J Microbiol Biotechnol 27:2221-2227

22. Cabrerizo M, Echevarria JE, González I et al (2008) Molecular epidemiological study of HEV-B enteroviruses involved in the increase in meningitis cases occurred in Spain during 2006. J Med Virol 80:1018-1024
23. Zhang H, Zhao Y, Liu H et al (2017) Molecular characterization of two novel echovirus 18 recombinants associated with handfoot-mouth disease. Sci Rep 7:8448

24. Shen H (2018) Recombination analysis of coxsackievirus B5 genogroup C. Arch Virol 163:539-544

25. Shen H, Liu T, Luo Y et al (2018) Echovirus plays major roles in the natural recombination of Coxsackievirus B3. J Med Virol 90:377-382

26. Kyriakopoulou Z, Amoutzias GD, Dimitriou TG et al (2018) Intraand inter-serotypic recombinations in the 5'UTR-VP4 region of Echovirus 30 strains. Arch Virol 163:365-375

27. Pu X, Qian Y, Yu Y et al (2019) Echovirus plays a major role in natural recombination in the coxsackievirus B group. Arch Virol 164:853-860

28. McWilliam Leitch EC, Bendig J, Cabrerizo M et al (2009) Transmission networks and population turnover of echovirus 30. J Virol 83:2109-2118

29. Nougairede A, Bessaud M, Thiberville SD et al (2014) Widespread circulation of a new echovirus 30 variant causing aseptic meningitis and non-specific viral illness, South-East France, 2013. J Clin Virol 61:118-124

30. Savolainen-Kopra C, Paananen A, Blomqvist S et al (2011) A large Finnish echovirus 30 outbreak was preceded by silent circulation of the same genotype. Virus Genes 42:28-36

31. Iwai M, Yoshida H, Matsuura K et al (2006) Molecular epidemiology of echoviruses 11 and 13, based on an environmental surveillance conducted in Toyama Prefecture, 2002-2003. Appl Environ Microbiol 72:6381-6387

32. Iwai M, Yoshida H, Obara M et al (2010) Widespread circulation of echovirus type 13 demonstrated by increased seroprevalence in Toyama, Japan, between 2000 and 2003. Clin Vaccine Immunol 17:764-770

33. Iwai M, Horimoto E, Obara M et al (2011) Endemic transmission of echovirus 30 in Toyama, Japan in 2010 is verified by environmental surveillance. Jpn J Infect Dis 64:165-167

34. Sedmak G, Bina D, MacDonald J (2003) Assessment of an enterovirus sewage surveillance system by comparison of clinical isolates with sewage isolates from Milwaukee, Wisconsin, collected August 1994 to December 2002. Appl Environ Microbiol 69:7181-7187

Publisher's Note Springer Nature remains neutral with regard to jurisdictional claims in published maps and institutional affiliations. 